$(c-16-920930-15$

GA-A--21043

DE93 004909

\title{
FAST WAVE CURRENT DRIVE SYSTEM DESIGN FOR DIII-D
}

\author{
by \\ J.S. deGRASSIE, F.W. BAITY, R. CALLIS, \\ D.J. HOFFMAN, Y.R. LIN-LIU, C.P. MOELLER, \\ C.C. PETTY, D.R. PHELPS, R.I. PINSKER, D. REMSEN, \\ D.J. TAYLOR, W. ARNOLD, and S. MARTIN
}

SEPTEMBER 1992

\section{GENERAL ATOMICS}




\section{DISCLAIMER}

This report was prepared as an account of work sponsored by an agency of the United States Government. Nejther the United States Government nor any agency thereof, nor any of their employees, makes any warranty, express or implied, or assumes any legal lisbility or responsibility for the accuracy, completeness, or usefulness of any information, apparatus, product, or process disclosed, or represents that its use would not infringe privately owned rights. Reference herein to any specific commercial product, process, or service by trade name, trademark, manufacturer, or otherwise, does not necessarily constitute or imply its endorsement, recommendation, or favoring by the United States Government or any agency thereof. The views and opinions of authors expressed herein do not necesaarily state or reflect those of the United States Government or any agency thereof. 
GA-A21043

\title{
FAST WAVE CURRENT DRIVE SYSTEM DESIGN FOR DIII-D
}

\author{
by \\ J.S. deGRASSIE, F.W. BAITY,* R. CALLIS, \\ D.J. HOFFMAN, ${ }^{*}$ Y.R. LIN-LIU, C.P. MOELLER, \\ C.C. PETTY, D.R. PHELPS, R.I. PINSKER, D. REMSEN, \\ D.J. TAYLOR, ${ }^{*}$ W. ARNOLD, ${ }^{\dagger}$ and S. MARTIN ${ }^{\dagger}$
}

This is a preprint of a paper to be presented at the Seventeenth Symposium on Fusion Technology, September 14-18, 1992, Roma, Italy and to be printed in the Proceedings.

Work supported by U.S. Department of Energy Contract Nos. DE-AC03-89ER51114, DE-AC08-89ER52153, and DE-AC03-84OR21400

* Oak Ridge National Laboratory, Oak Ridge Tennessee.

${ }^{\dagger}$ ANT Nachrichtentechnik GmbH, Backnang, Germany.

GENERAL ATOMICS PROJECT 3466 SEPTEMBER 1992
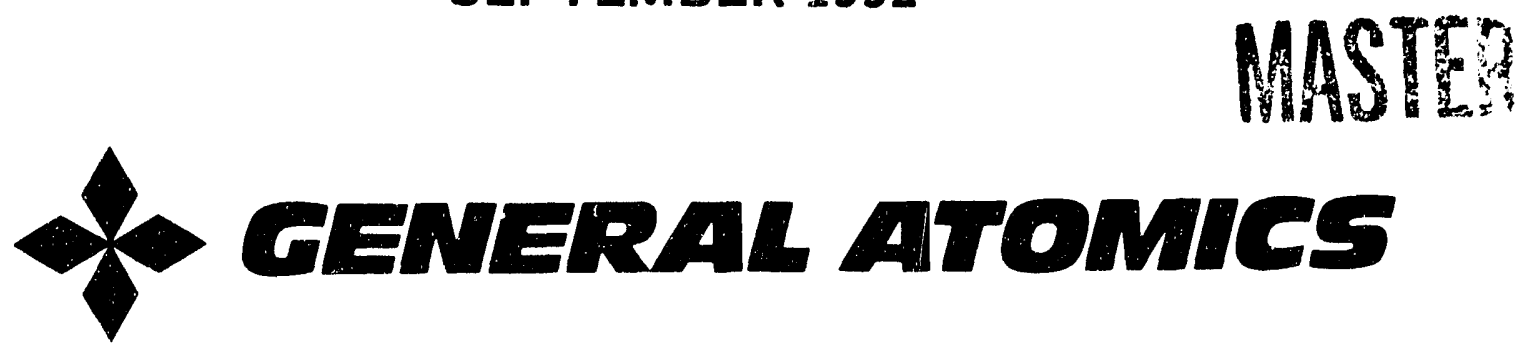


\title{
FAST WAVE CURRENT DRIVE SYSTEM DESIGN FOR DIII-D
}

\author{
J.S. deGRASSIE, F.W. BAITY, ' R. CALLIS, D.J. HOFFMAN, ${ }^{\perp}$ Y.R. LIN-LIU, \\ C.P. MOELLER, C.C. PETTY, D.R. PHELPS, R.I. PINSKER, D. REMSEN, D.J. TAYLOR, 1 \\ W. ARNOLD, ${ }^{2}$ and S. MARTIN ${ }^{2}$
}

General Atomics, P.O. Box 85608, San Diego, California 92186-9784

1Oak Ridge National Laboratory, P.O. Box 2008, Oak Ridge, Tennessee 37831

${ }^{2}$ ANT Nachrichtentechnik GmbH, Gerberstrasse 33 W-7150, Backnang, Germany

\begin{abstract}
DIII-D has a major effort underway to develop the physics and technology of fast wave electron heating and current drive in conjunction with electron cyclotron heating. The present system consists of a four strap antenna driven by one $2 \mathrm{MW}$ transmitter in the 32-60 MHz band. Experiments have been successful in demonstrating the physics. of heating and current drive. In order to validate fast wave current drive for future machines a greater power capabiltiy is necessary to drive all of the plasma current. Advanced tokamak modeling for DIII-D has indicated that this goal can be met for plasma configurations of interest (i.e. high $\beta$ VH-mode discharges) with $8 \mathrm{MW}$ of transmitter fast wave capability. It is proposed that four transmitters drive fast wave antennas at three locations in DIII-D to provide the power for curent drive and current profile modification. As the next step in acquiring this capability, two modular four strap antennas are in design and the procurement of a high power transmitter in the $30-120 \mathrm{MHz}$ range is in progress. Additionally, innovations in the technology are being investigated, such as the use of a coupled combline antenna to reduce the number of required feedthroughs and to provide for parallel phase velocity variation with a relatively small change in frequency, and the use of fast ferrite tuners to provide millisecond timescale impedance matching. A successful test of a low power fast ferrite prototype was conducted on DIII-D.
\end{abstract}

\section{INTRODUCTION}

One of the goals for the DIII-D experimental program during the 1990 s is to establish experimentally the physics and efficiency optimization of if current drive.
Once validated, this capability will be combined with optimized DIII-D advanced tokamak configurations to demonstrate long-pulse (10-20 s) fully non-inductive current drive. Because of the attractive scaling to reactor parameters, the fast Alfvén wave has been selected as the primary current drive technique for DIII-D. Fast wave current drive (FWCD) will be supplemented by electron cyclotron current drive and by bootstrap current for noninductive current operation.

A 2 MW FWCD system (Ref. 1) has been in operation on DIII-D since late 1990 . This system has successfully operated according to the design described in Ref (1), which predated the start of the experiments. The FW program on DIII-D is a collaborative effort between General Atomics and the Oak Ridge National Laboratory. This system is the first step in developing the FW power capability necessary to demonstrate noninductive if current drive.

Initial experimental results have been very encouraging. Boch direct electron heating by the fast waves (Ref. 2) and current drive (Refs. 3,4) have been demonstrated, with the expected magnitude. The technology of the FW system, including the transmitter, transmission and matching network, and antenna have operated successfully (Refs. 5-7). Feedback control of the plasmaantenna gap to aid in holding the impedance match between the generator and plasma load was demonstrated using the new digital control system recently commissioned on DIII-D (Ref. 8). These initial results provide the basis for enhancing the FW capability in order to give a clearer validation of FWCD, which will require sufficient power to drive all of the plasma current to eliminate effects due to the residual electric field and to non-inductively sustain advanced tokamak plasma configurations.

In addition to adding greater power capability, we are investigating some technical innovations which could make an ultimate reactor FWCD system more 
versatile and robust. First. we are evaluating the use of real time dynam.ic ferrite runers (Ref. 9) to maintain the match between the generator and the antenna throughout plasma load variations caused, for example, by $\mathrm{H}$-mode transitions, ELMs and so on. These variations can take place on the millisecond timescale in DIII-D. Dynamic ferrite tuners are well established in the realm of accelerator technology and a preliminary test of a prototype on DIII-D was successful. In the most extensive application of this technology the experimentalists will gain continuous strap to strap phase control while presenting a match to the generator, thereby maintaining continuous resonance with the desired multiple of the electron thermal velocity as the plasma heats up throughout a shot, or during the initialization of reactor operation (variable $n$ parallel).

Another way to obtain some real time variation in the launched $\mathrm{k}$ spectrum is to use a combline structure for the antenna (Ref. 10). This is a multi-strap antenna requiring only two feed points, one at the input and one at the output. The matching of this antenna to the generator is much simpler than for separately fed current straps with a strong strap to strap coupling (Ref. 7).

\section{PROPOSED 8 MEGAWATT FAST WAVE SYSTEM}

Extensive modeling of advanced tokamak scenarios for DIII-D indicate that the proposed goals can be met with an $8 \mathrm{MW}$ (generator power) FW system accompanied by $10 \mathrm{MW}$ of electron cyclotron heating power (gyrotron source power) at $110 \mathrm{GHz}$. A layout of the three FW antennas is depicted in Fig. 1. Shown are two four strap antennas, FW2A and FW2B, located in midplane ports at $0^{\circ}$ and $180^{\circ}$ toroidally, and a combline antenna, FW3, located in the port box spanning the $285^{\circ}$ and $300^{\circ}$ midplane location. The present ORNL four strap antenna, FW1, is at this latter location (Ref. 1), and our present plan is to eventually replace it with a 10-20 s pulse combline as shown (FWl is designed with only a $2 \mathrm{~s}$ pulse capability).

A total of $8 \mathrm{MW}$ of FW power will be available at the generators, of which only $2 \mathrm{MW}$ at $30-60 \mathrm{MHz}$ is now on hand at DIII-D. The next increment of power will operate over the $30-120 \mathrm{MHz}$ range, with over $2 \mathrm{MW}$ output at the lower end of the band and $1.5 \mathrm{MW}$ at $120 \mathrm{MHz}$. The addition of the final generator power will be specified in the future. One possible network of generators and antennas is shown in Fig. 2. The tuning and matching scheme shown for the two four strap antennas utilizes the simple solution developed for FW1 to allow $\pi / 2$ phasing (current drive) in the presence of large strap-strap coupling, but with the addition of a decoupler such as is being developed by ORNL for JET (Ref. 11). The tuning network would of course be different with the inclusion of fast ferrite tuners to give real time control of phasing and matching.

The decoupler is important for the DIII-D design in which four mutually coupled straps are fed by one

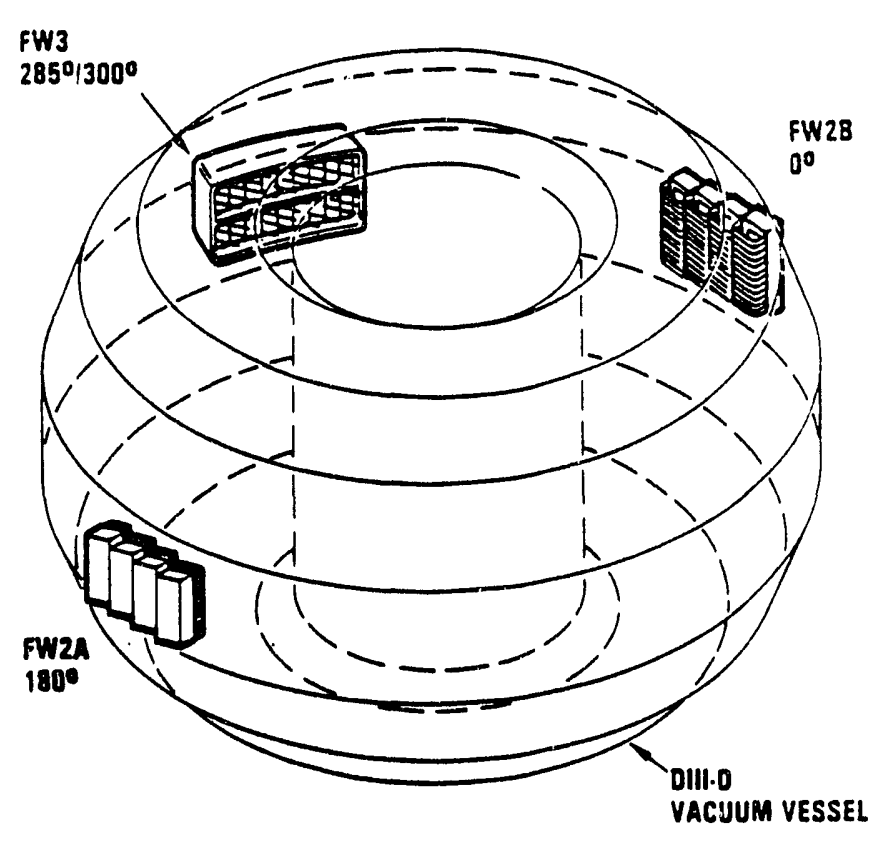

Fig. 1. Fast wave antenna locations on DIII-D for future experiments. Present antenna is one four-strap located at $285^{\circ} / 300^{\circ}$.
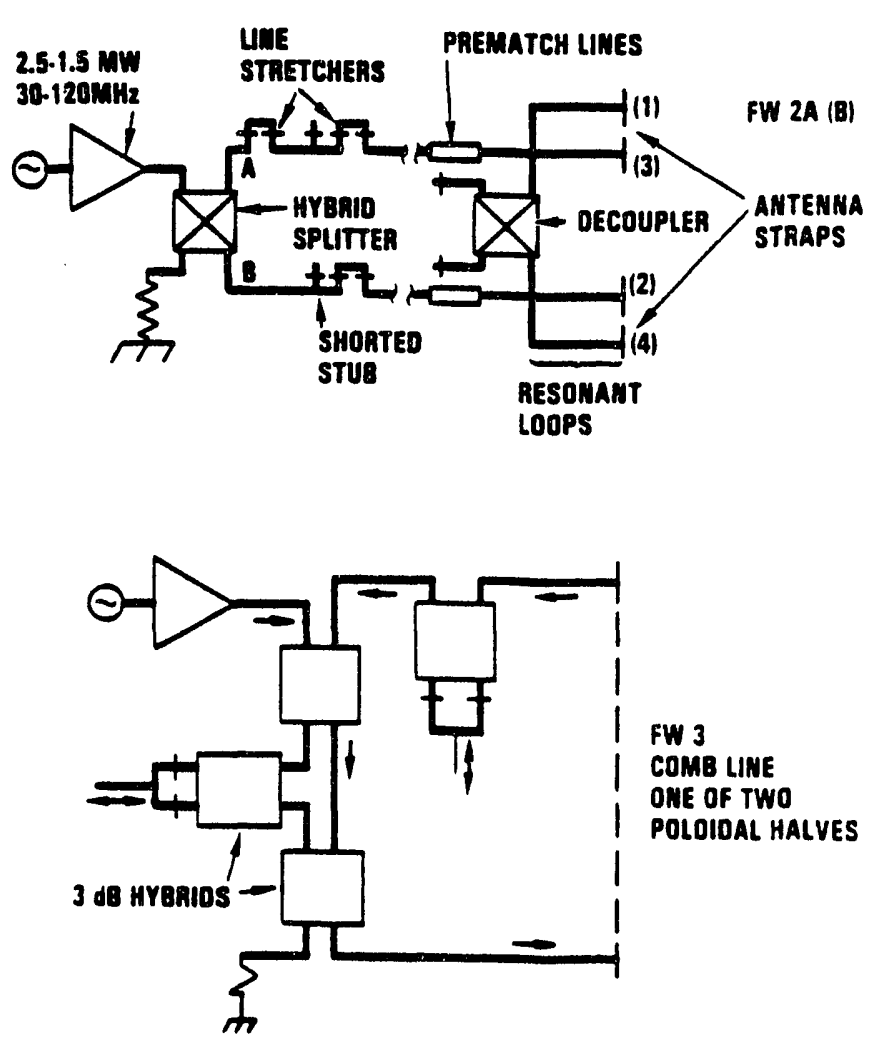

Fig. 2. A transmission feed design for the antennas.

generator with a $\pi / 2$ phase shift between adjacent straps to launch a directed spectrum for current drive. Without 
the decoupler, the power split between lines $A$ and $B$ is not equal (Ref. 7), one line can have many times the power as the other. Although this unequal power split can be accomplished by using a tee in the transmission line (Ref. 7), the A and B transmission and tuning legs must be specified to handle this worst case power level. Operation at $\pm \pi / 2$ phasing means that either can have the high level. With the decoupler this imbalance is removed and the specifications for the lines can be relaxed.

The combline antenna is being proposed to take advantage of the ability to change parallel wavenumber with a small change in frequency (Ref. 10). This will allow another way to maintain resonance with the electron thermal velocity without requiring an array of fast tuning elements. Also a combline requires only two power feedthroughs. In a reactor the combline could be placed between ports rather that occupying valuable port space.

The recirculating drive circuit for the combline shown in Fig. 2 is taken from Ref. (10), where two poloidally segmented comblines are proposed. This gives a more favorable poloidal current spectrum for $120 \mathrm{MHz}$ operation. Thus the combline circuit in Fig. 2 will be duplicated for the upper and lower combline.

\section{FW2 ANTENNAS}

The FW2 four strap antennas are presently in design at ORNL, with installation in DIII-D targeted for early 1994. The antennas are designed to be modular with the antenna consisting of an array of four modules mounted side by side in the DIII-D port openings as shown in Fig. 3. Each antenna module is capable of handling $1 \mathrm{MW}$ for pulses up to $20 \mathrm{~s}$ long so that a total antenna capability of four $\mathrm{MW}$ is provided per port opening. The four antenna modules are fed by transmission lines that go through vacuum feedthroughs on the port cover.

Each module consists of a cavity box, tilted Faraday shield, current strap, and coax conductors. Rf and plasma heat deposited in the antenna will be removed by water cooling all of the components of each module. By making the antenna modular, fabrication costs are reduced, while at the same time providing a way to pressure and leak test each module before it is installed in the tokamak. In addition, any of the modules may be removed or replaced in the array without removal of the entire antenna. The modules will be bolted together upon installation and the array will be bolted to a mounting plate installed to the vacuum vessel port box. All disruption loads on the antenna will be transferred to the vaccuum vessel through the mounting plate.

The current straps have two ground points. One end of the strap is grounded to the bottom of the cavity, while the other end of the strap is grounded to the cavity side wall. A single tap is provided on the back of the strap by welding the center coax to the strap.

Each antenna module is designed to have its own Faraday shield (FS). Although we are still investigating the possibility of being able to omit this shield, we have

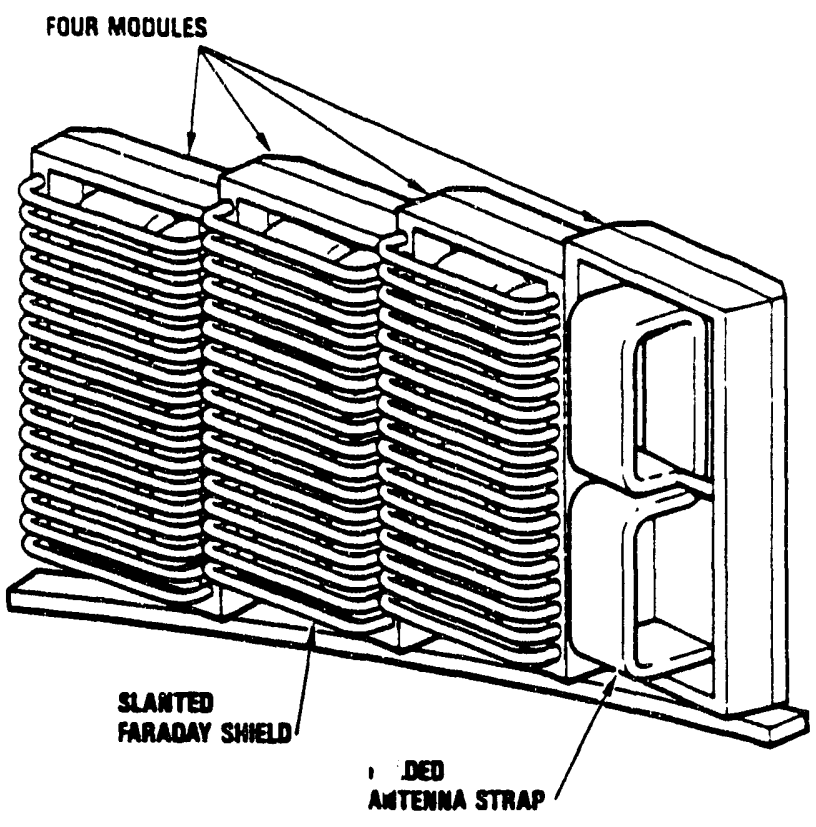

Fig. 3. Modular design for antennas FW2A(B).

not yet demonstrated the ability to operate with directed antenna phasing for current drive with no shield. Without such an experimental demonstration the FW2 antennas are designed with shields. TEXTOR is performing a series of experiments on operation without FS, and the results have been encouraging (Ref. 12). On DIII-D operation without a FS was attempted on several run days over a period of months in the first half of 1992. direct electron heating was successful in the symmetric antenna phasing mode ( $\pi$ phase shift between straps) and impurity generation was not a problem due to boronization of the DIII-D vessel and antenna straps. However, the FW1 antenna was not designed for use without a shield, the antenna structure is relatively open and there are no intrastrap limiters to reduce plasma cross field diffusion or generation (Ref. 1). This antenna configuration did exhibit arcing at power levels below that with FS. A complete comparison could not be made due to limited operational time and problems in the if transmitter and the transmitter system which enforced an additional limit in the available if power. Operation without a FS has been concluded for the present and the next phase of experiments will be conducted with a new slanted FS coated with $\mathrm{B}_{4} \mathrm{C}$.

\section{FAST FERRITE TUNER TEST ON DIII-D}

During the last week of the FY92 DIII-D experimental campaign a fast ferrite tuner prototype from ANT Bosch Telecom was tested at low power on one strap of the FW1 antenna. The electrical topology of the tuner consisted of a $3 \mathrm{~dB}$ hybrid with ferrite loaded stubs of variable electrical length, tunable by the bias 
magnetic field applied. The goal of the test was to find the rate with which this matching element could respond to dynamic plasma loading conditions. Fixed element pretuning is incorporated into the stubs of this fast ferrite hybrid (FFH) in order to move the domain of possible mismatch into the accessible region. Since a change in the magnetic permeability of the ferrite causes a change in the impedance of the loaded section of line, the ferrite loaded line cannot in general be used as a line stretcher. Rather it is implemented by variable electrical length shorted stubs.

A schmatic of the set-up depicting the key elements is shown in Fig. 4. The FFH utilizes two fast ferrit Tuners (FFT) (Ref. 9) as shown. A feedback loop monitors the complex reflection coefficient at the outport of the FFH and controls the magnet power supplies on FFT1 and FFT2 to null out this reflection. During the tests, the DIII-D FW Tuner shorted stub was electrically removed from the circuit by setting a $90^{\circ}$ electrical length, and the line stretcher was used to move the antenna load into the accessible mismatch region (AMR) of the FFH, rather than taking the time to physically change the line segments on the FFH.

Tests were conducted on DIII-D in a background mode. No FW heating was used, rather only low power antenna strap - plasma matching was accomplished with the FFH. The tests successfully demonstrated the ability of the tuner to respond to essentially instantaneous changes in loading with less than a 20 millisecond response time. Figure $5(a)$ shows this response time in the reduction of the magnitude of the reflection coefficient, $r$, while fig. 5(b) shows the polar trajectory of the decaying reflection coefficient over this time period on a Smith chart The AMR of the FFH for this case is also shown in Fig. 5(b).

The overall reaction time of this FFH was not this fast due to a bottleneck in the digital transfer of data from a network analyzer, used for measurement of the

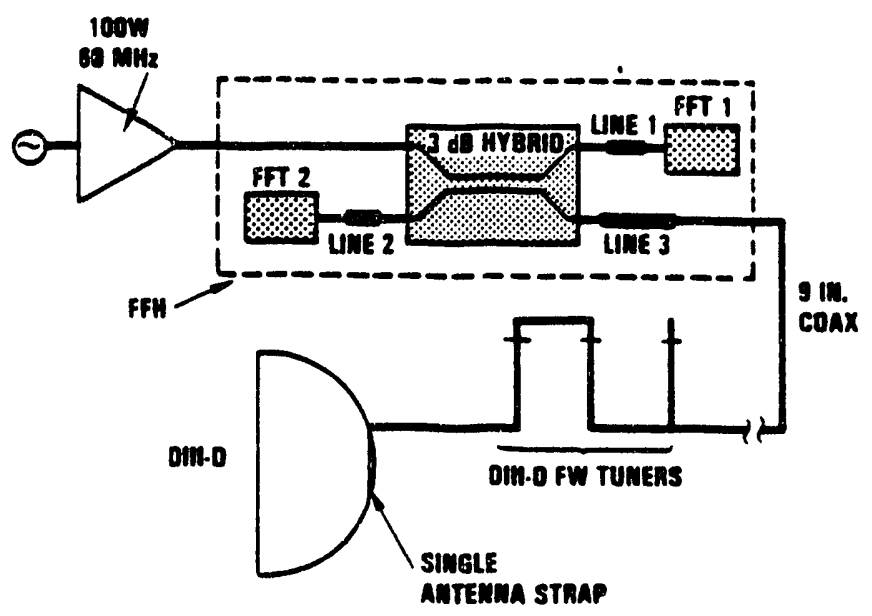

Fig. 4. Schematic of test setup for low power fast feritte hybrid tuner. (a)

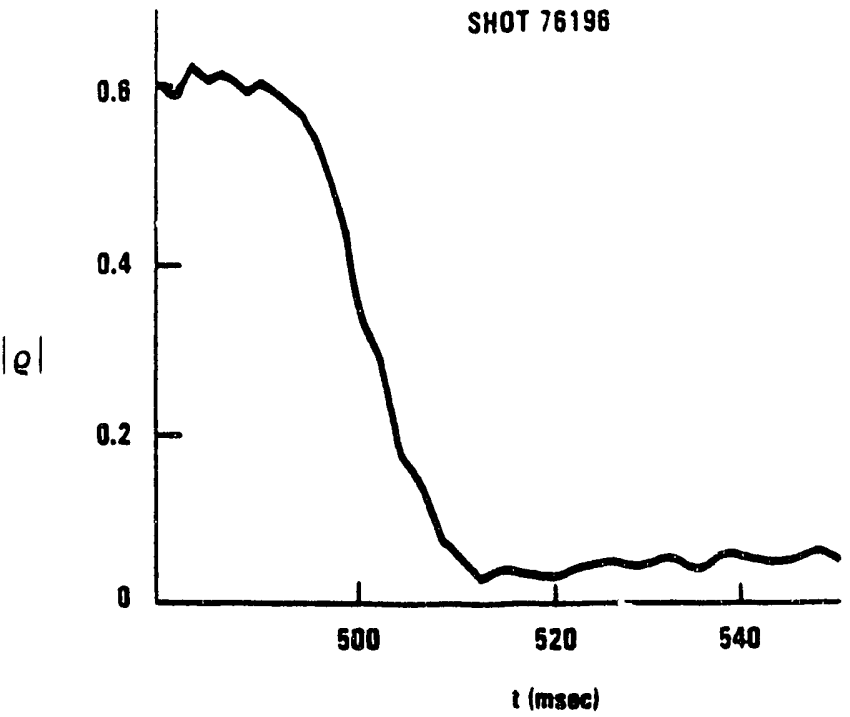

(b)

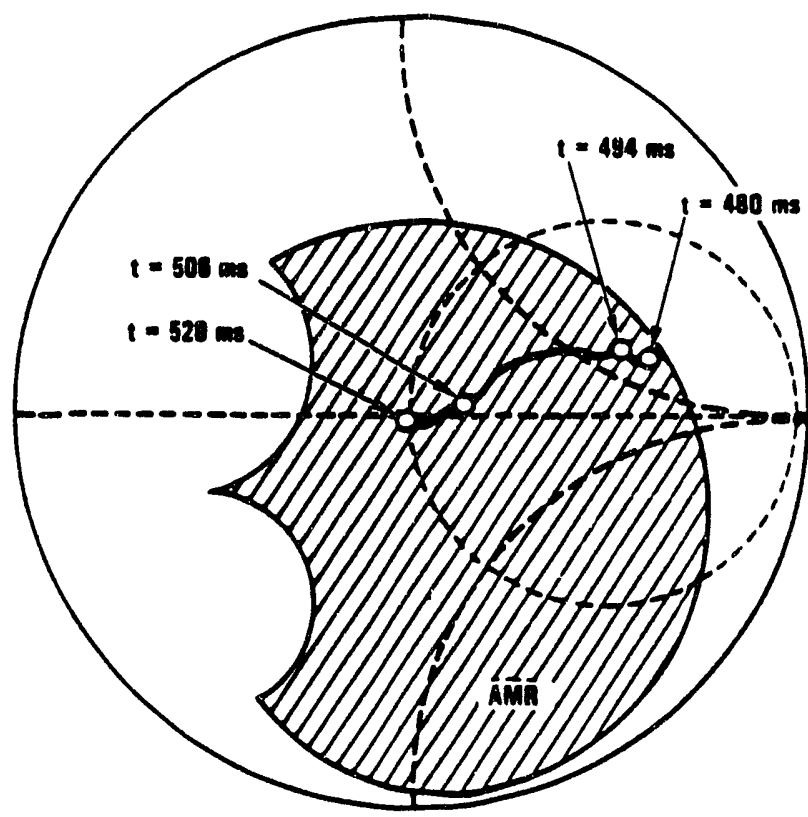

Fig. 5. (a) Response time in reduction of the magnitude of the reflection coefficient, $\rho$, at the output of the generator during a DIII-D discharge. (b) Trajectory of $\rho$ during this time displayed on a Smith chart.

reflection coefficient, to a microcomputer used to calculate and command the required coil currents which generate the bias magnetic fields on the ferrite stubs. This overall reaction time was greater than $200 \mathrm{~ms}$. Once the command was given by the computer the physical response of the system was less than $20 \mathrm{~ms}$ as shown in Fig. 5. Future versions of the FFH will avoid this bottleneck with customized digital hardware. Then, the only limitation in response will be the time necessary to change the bias magnetic field on the ferrites. Design improvements can bring this down to the millisecond timescale. 


\section{CONCLUSION}

The fast wave heating and current drive program on DIII-D has had a successful start. The results indicate that an $8 \mathrm{MW}$ transmitter capability in the 60-120 MHz range can lead to attainment of fully noninductive current drive, when coupled with ECH for additional electron heating.

An $8 \mathrm{MW}$ system has been designed, consisting of four transmitters driving antennas at three toroidal locations in DIII-D. Two of these are modular four strap antennas now in design at ORNL. The third antenna design is yet to be decided. Here, we have proposed a poloidal pair of combline antennas for this third location.

One potential upgrade is to make use of fast ferrite devices to maintain a real time match between the plasma load and generator impedances, and to change the strap to strap phase shift rapidly, within a shot. Low power coupling tests on DIII-D demonstrated that a fast ferrite hybrid can, in principle, respond fast enough for real time matching.

\section{ACKNOWLEDGEMENT}

This work was supported by the U.S. Department of Energy under Contract Nos. DE-AC03-89ER51114, DE-AC03-89ER52153, and DE-ACO3-84OR21400.

\section{REFERENCES}

1. F.W. Baity, et al., "Fast Wave Current Drive System for DIII-D," in Proc. of 16th Symp. on Fusion Technology, 1990, p. 103.

2. C.C. Petty, et al., "Absorption of Fast Waves by Electrons on the DIII-D Tokamak," Phys. Rev. Lett. 69, 289 (1992).
3. R. Prater, et al., "Current Drive with Fast Waves, Electron Cyclotron Waves, and Neutral Injection in the DIII-D Tokamak." J. Fusion Technol., to be published.

4. R.I. Pinsker, et al., "Direct Electron Heating and Current Drive with Fast Waves in DIII-D," Proc. of the 14th Conf. on Plasma Physics and Controlled Nuclear Fusion Research, IAEA 1992. Wurzburg, to be published.

5. M.J. Mayberry, et al., "Fast Wave Current Drive Antenna Performance on DIII-D," in AIP Conference, Proc. 244, RF Power in Plasmas, 1991, p. 276.

6. R.H. Goulding, et al., "Design and Performances of Fast Wave Current Drive Systems in the ICRF," ibid, p. 287.

7. R.I. Pinsker, et al., "30-60 MHz FWCD System on DIII-D: Power Division, Phase Control and Tuning for a Four Element Antenna Array," Proc. 14th IEEE Symp. on Fusion Engineering, San Diego, 1991, p. 115.

8. J. Ferron, et al., "A High Speed Data Acqusition and Procesing System for Real Time Data Analysis and Control," Review of Scientific Instruments, to be published.

9. S. Martin, W. Amold, and E. Pivit, "A Fast Double Mode Tuner for Antenna Matching," in AIP Conference Proc. 244, RF Power in Plasmas, 1991 , p. 318.

10. C.P. Moeller, S.C. Chiu, and D.A. Phelps, "A Combline Structure for Launching Unidirectional Fast Waves," Europhys. Conf. Abs. 16E, RF Heating and Current Drive in Fusion Development, 1992, p. 5.

11. R.H. Goulding., Proc. of 17th Symp. on Fusion Technology, 1992.

12. R. VanNiewenhave, et al., "Ion Cyclotron Resonance Heating of a Tokamak Plasma Using an Antenna Without a Faraday Shield," Nucl. Fusion 31, 1770 (1991). 

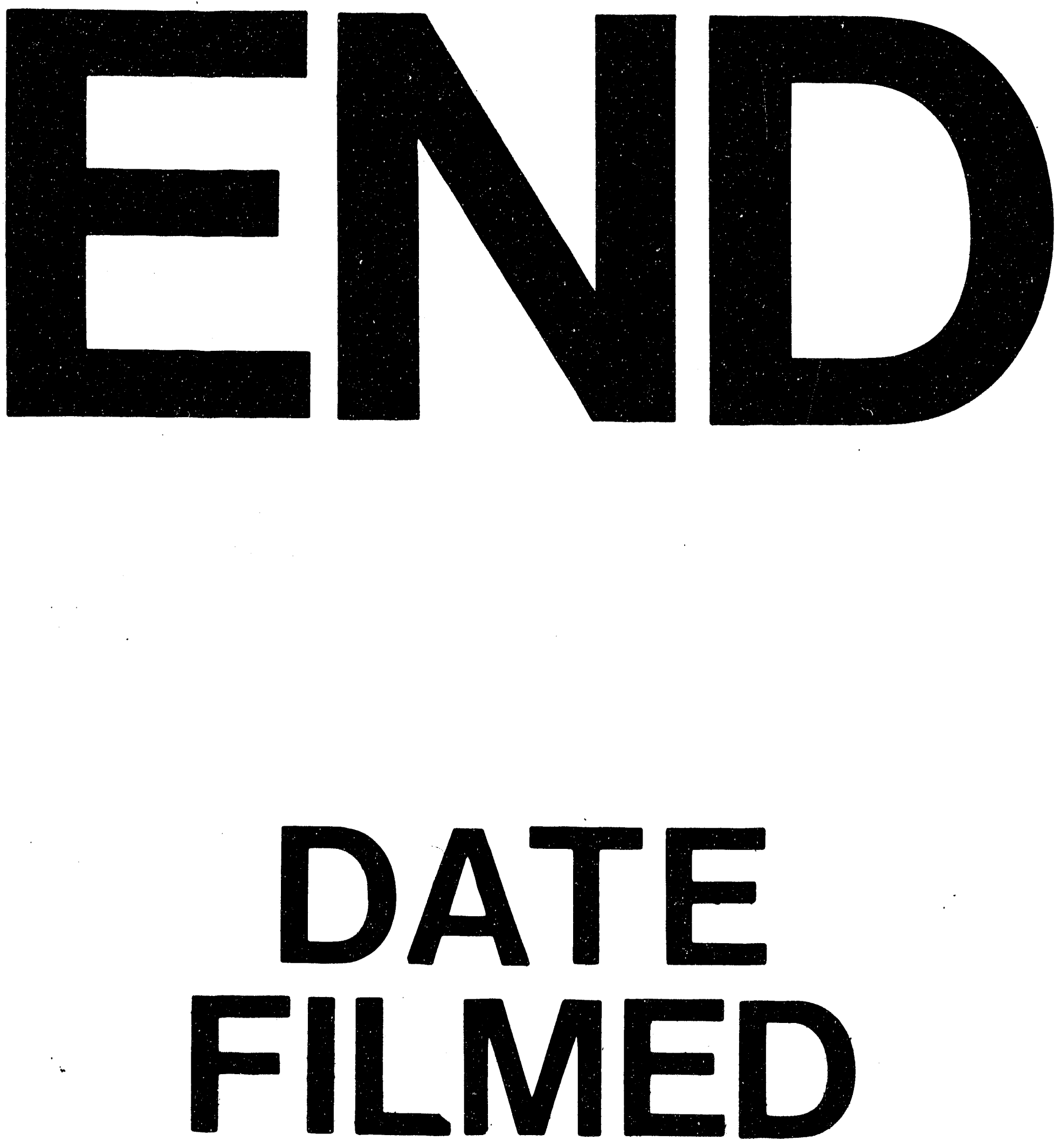

1

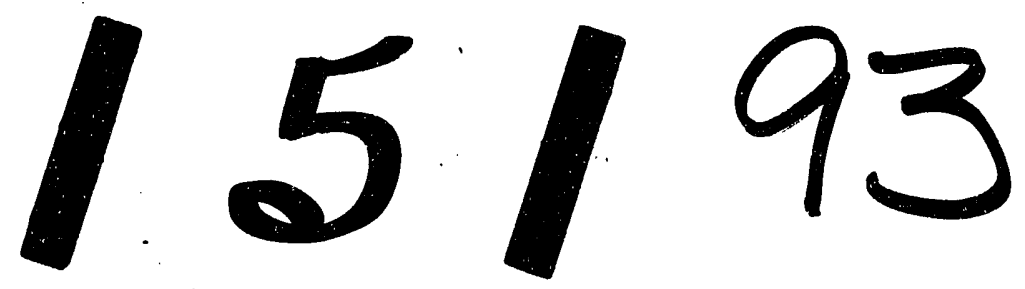


